\title{
Canine amniotic membrane derived mesenchymal stem cells exosomes addition in canine sperm freezing medium
}

\author{
Feriel Yasmine Mahiddine ${ }^{1}$, Ahmad Yar Qamar ${ }^{2,3}$ and Min Jung Kim ${ }^{1, *}$ \\ ${ }^{1}$ Department of Theriogenology and Biotechnologies, College of Veterinary Medicine, Seoul National University, Seoul \\ 08826, Korea \\ ${ }^{2}$ Laboratory of Theriogenology, College of Veterinary Medicine, Chungnam National University, Daejeon 34134, Korea \\ ${ }^{3}$ Department of Clinical Sciences, College of Veterinary and Animal Sciences, Jhang 35200, Sub-Campus University of \\ Veterinary and Animal Sciences, Lahore 54000, Pakistan
}

Received July 20, 2020

Revised August 10, 2020

Accepted August 10, 2020

*Correspondence

Min Jung Kim

E-mail: tinia19@snu.ac.kr

ORCID

https://orcid.org/0000-0003-0512-155X

\begin{abstract}
Amniotic membrane stem cells are considered as a good alternative to embryonic stem cells, but their use in clinical studies is still not common. Here, exosomes from canine amniotic membrane mesenchymal stem cells (cAmMSCexo) were used for dog sperm cryopreservation. Upon cryopreserved straws using cryoprotectant containing $0,0.5,1$, or $2 \mu \mathrm{g} / \mathrm{mL}$ of cAmMSC-exo were thawed, motility and membrane integrity were analyzed. However, results showed no significant differences between the groups. We concluded that cAmMSC-exo with lower than 2 $\mu \mathrm{g} / \mathrm{mL}$ have no effects on sperm cryopreservation, and further studies to get higher concentrations of cAmMSC-exo should be conducted for clinical application.
\end{abstract}

Keywords: amniotic membrane, dog sperm, exosomes, mesenchymal stem cells, sperm cryopreservation

\section{INTRODUCTION}

Exosomes have been discovered in 1983 (Pan and Johnstone, 1983) and are defined as 40-100 nm extracellular vesicles originating from the fusion of multi-vesicular bodies, also referred to as late endosomes, with the plasma membrane. They are known to mediate cell-to-cell communication as they can carry proteins, nucleic acids, and lipids, providing through that cargo a paracrine effect to the recipient tissues or cells (Mitchell et al., 2019). Thus, stem cell-derived exosomes have been used as a shuttle in cell-free therapies for the treatment of different conditions such as kidney diseases (Dorronsoro and Robbins, 2013) or osteoarthritis (Zhang et al., 2019). Among stem cell types, perinatal tissue-derived stem cells are a good alternative to embryonic stem cells as they are obtained without major ethical issues since they come from discarded fetal annexa, but the use of their secretome is still not common as there are over 30 clinical trials using perinatal tissue-derived stem cells but less than 10 trials using their derived exosomes (https://clinicaltrials.gov/). Among the perinatal tissues, the amniotic membrane is a good source of mesenchymal stem cells (Alviano et al., 2007) but the use of these stem cells or their derived exosomes is not as spread out as the other stem cells types, although they have the same properties and their secretome is as rich in growth and anti-apoptotic factors (An et al., 2017). 
Canine sperm cryopreservation is regularly performed by veterinarians in practice and research laboratories, but due to cryoinjuries and the deleterious effects on sperm post-thaw parameters, it still faces some hurdles during this process. Cryoinjuries affect spermatozoa cells membranes due to osmotic changes and it increases sperm DNA fragmentation which leads to low post-thaw parameters and a high percentage of dead sperm. To prevent that, penetrating and non-penetrating cryo-protectants have been added in the freezing media with antioxidants such as vitamin $\mathrm{E}$ to protect DNA integrity and anti-apoptotic factors.

Exosomes derived from mesenchymal stem cells carry anti-oxidants, anti-apoptotic, and growth factors (Zhou et al., 2013), which makes them ideal candidates for a new cryopreservation protocol to improve post-thaw sperm parameters. Thus, the aim of this study was to evaluate the effects of canine amniotic membrane mesenchymal stem cells derived exosomes (cAmMSCs-exo) on canine sperm cryopreservation.

\section{MATERIEL AND METHODS}

\section{Cell culture and exosomes extraction}

Canine amniotic mesenchymal stem cells (cAmMSC) and its culture media (RPME-5) were provided from Naturecell Co., Ltd (Seoul, Republic of Korea). cAmMSCs were cultured with the culture media up to $80 \%$ confluency at passage 3 when serum-free Dulbecco's Modified Eagle Medium was added to the cells. After $48 \mathrm{~h}$, the conditioned media was retrieved and centrifuged at $2.000 \mathrm{~g}$. for $30 \mathrm{~min}$. Exosomes were extracted using total isolation reagent (Invitrogen ${ }^{\mathrm{TM}}$, Vilnius, Lithuania) according to the manufacturer's instructions. Exosomes were identified under transmission electron microscopy after staining with $2 \%$ uranyl acetate, and Bradford assay was conducted for protein quantification.

\section{Animal use and semen processing}

All dogs used for the study were housed under the same conditions, in individual cages and were fed with commercial adult dry food and water daily. All experiments were conducted in accordance with recommendations described in "The Guide for the Care and Use of Laboratory Animals" published by the Institutional Animal Care and Use Committee (IACUC) of Seoul National University (ap- proval number: SNU-180731-2-1). Semen was obtained by digital manipulation, twice a week from five beagle dogs. Only the second fraction of the ejaculate was collected, then the samples were pooled to avoid individual variations and washed.

\section{Cryopreservation and thawing process}

Semen was diluted with Tris-extender $(1: 1, \mathrm{v} / \mathrm{v})$ and centrifuged at $700 \mathrm{~g}$ for $1 \mathrm{~min}$. The supernatant was collected and centrifuged at $400 \mathrm{~g}$ for $5 \mathrm{~min}$ and only the pellet was re-suspended with TRIS buffer to adjust the concentration of $100 \times 10^{6}$ sperm cells $/ \mathrm{mL}$ when Tris-egg yolkglycerol extender with or without exosome proteins (0.5, 1 or $2 \mu \mathrm{g} / \mathrm{mL}$ ) will be added. The samples were loaded in $0.5 \mathrm{~mL}$ straws (Minitube, Tiefenbach, Germany) by multistep protocol (Setyawan et al., 2015), sealed, kept at $4^{\circ} \mathrm{C}$ during $1 \mathrm{~h}$ for equilibration, and were frozen horizontally $10 \mathrm{~cm}$ above liquid nitrogen (LN2) for $15 \mathrm{~min}$ before being transferred to LN2 tanks $\left(-196^{\circ} \mathrm{C}\right)$. A week after, straws were thawed in a $37^{\circ} \mathrm{C}$ water bath for $30 \mathrm{~s}$, then $14 \%, 19 \%$, $27 \%$, and $40 \%$ TRIS extender was added every $30 \mathrm{~s}$.

\section{Sperm parameters evaluation}

Post-thaw parameters were evaluated with a computerassisted sperm analysis system (CASA) (FSA2011 premium edition version 2011, Medical Supply Co., Ltd., Korea) and a hypo-osmotic swelling test (HOST). Briefly, $100 \mu \mathrm{L}$ of sperm were added to $1 \mathrm{~mL}$ of a hypo-osmotic solution (150-155 mOsm) and incubated at $37^{\circ} \mathrm{C}$ for $30 \mathrm{~min}$. A drop

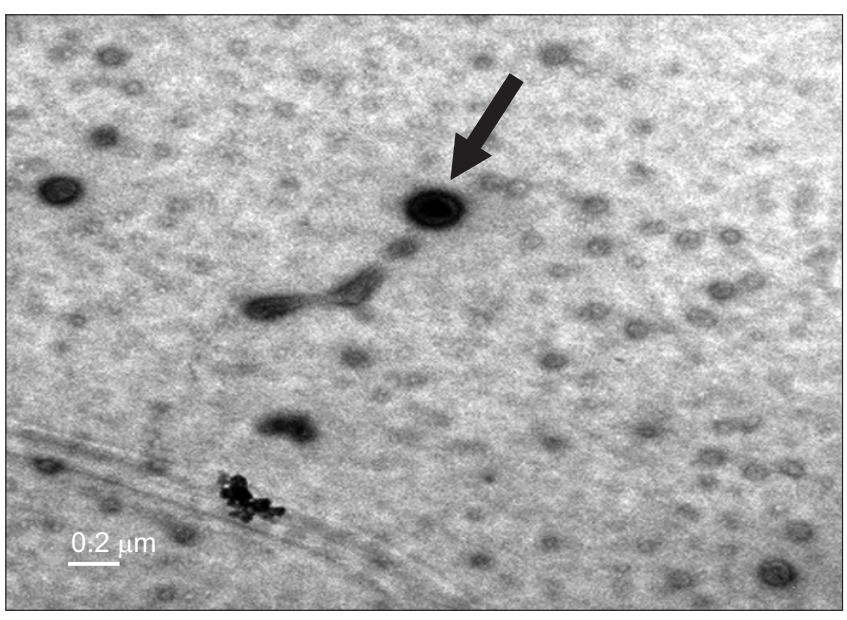

Fig. 1. Transmission electron microscopy image of exosomes (arrow) extracted from canine amniotic membrane stem cells conditioned media. 
of HOST solution with sperm was then put on a warm slide, covered and at least 100 sperm cells were counted under a microscope. All data were analyzed by one-way analysis of variance (ANOVA) followed by Tukey's multiple comparison test using GraphPad Prism 5.0 (Graphpad, San Diego, CA, USA). Values are presented as means \pm standard error of the mean, and $p$ values less than 0.05 were considered to be statistically significant.

\section{RESULTS AND DISCUSSION}

Exosomes were extracted from $40 \mathrm{~mL}$ of conditioned media; $10 \mathrm{~mL}$ were used for protein quantification, to obtain a yield of $35.7 \pm 6.5 \mu \mathrm{g}$ of exosome proteins, and the rest $(30 \mathrm{~mL})$ was used for sperm cryopreservation or electron microscopy. Exosomes were identified under transmission electron microscopy with a size ranging from 50 to $200 \mathrm{~nm}$ (Fig. 1). Upon sperm straws were thawed in $37^{\circ} \mathrm{C}$ for $1 \mathrm{~min}, \mathrm{CASA}$ or HOST were used right away for motility and velocity parameters or membrane integrity check respectively. There were no significant differences among the groups $(0,0.5,1$ or $2 \mu \mathrm{g} / \mathrm{mL})$ in post-thaw sperm parameters including motility, vitality, average curvilinear velocity (VCL), straight line velocity (VSL), average path velocity (VAP), linearity (LIN, average ratio of VSL/VCL), straightness (STR, average value of the ratio VSL/VAP), amplitude of the lateral movement of the head (ALH) (Table 1), and they were on the reference ranges (Park et al., 2018). As for HOST results, although the statistical analysis showed no significant differences, the group treated with $2 \mu \mathrm{g} / \mathrm{mL}$ of exosome proteins showed the highest percentage of intact membrane $61.3 \pm 7.4 \%$ compared with the control group, $0,0.5$, and $1 \mu \mathrm{g} / \mathrm{mL}$ of exosome proteins treatment groups with $51.3 \pm 4.3,56.5$ \pm 5.7 and $55.4 \pm 2.9 \%$ respectively (Table 2 ).

The use of exosomes in sperm cryopreservation is still new and up to date, only two studies have been reported (Mokarizadeh et al., 2013; Qamar et al., 2019). Paracrine secretions of mesenchymal stem cells are responsible for their therapeutical effects and stem cell-derived exosomes are known to carry anti-apoptotic and growth factors, chemokines, cytokines, mRNA, and miRNA (Zhou et al., 2013). We hypothesized that these anti-apoptotic and growth factors carried in exosomes could have beneficial effects on canine post-thaw sperm. Exosomal concentrations used in studies vary a lot as some experiments are successfully carried with low concentrations and others with high concentrations. Taking into consideration that exosomes can be obtained from different types of cells, each type of cell probably has different yields of exosomes with different contents. As for high concentrations of exosomes, experimental dosages vary from $50 \mu \mathrm{g} /$ $\mathrm{mL}$ to $500 \mu \mathrm{g} / \mathrm{mouse}$ (Mokarizadeh et al., 2013; An et al., 2017; Qamar et al., 2019), and for cryopreservation, exosomes have been used at concentrations ranging from 25 to $100 \mu \mathrm{g}$ of exosome proteins with beneficial obtained at the concentrations of 50 and $100 \mu \mathrm{g}$ (Mokarizadeh et al., 2013; Qamar et al., 2019) with the concentration of 50 $\mu \mathrm{g} / \mathrm{mL}$ having protective and regenerative effects. For low concentrations, $30 \mu \mathrm{g} / \mathrm{mL}$ of amniotic fluid stem cells derived exosomes have anti-apoptotic effects on granulosa cells exposed to chemotherapy, and the same effects were

Table 2. Hypo-osmotic swelling test results of post-thaw dog sperm using different concentrations of exosomes extracted from canine amniotic membrane stem cells conditioned media

\begin{tabular}{cc}
\hline Concentration $(\mu \mathrm{g} / \mathrm{mL})$ & Intact membrane (mean \pm SEM) \\
\hline 0 & $51.3 \pm 4.3$ \\
0.5 & $56.5 \pm 5.7$ \\
1 & $55.4 \pm 2.9$ \\
2 & $61.3 \pm 7.4$ \\
\hline
\end{tabular}

All results show means \pm SEM.

Table 1. Post-thaw sperm parameters using different concentrations of exosomes extracted from canine amniotic membrane mesenchymal stem cells conditioned media

\begin{tabular}{|c|c|c|c|c|c|c|c|c|}
\hline Concentration $(\mu \mathrm{g} / \mathrm{mL})$ & Motility (\%) & Vitality (\%) & $\mathrm{VCL}(\mu \mathrm{m} / \mathrm{sec})$ & VSL $(\mu \mathrm{m} / \mathrm{sec})$ & VAP $(\mu \mathrm{m} / \mathrm{sec})$ & LIN (\%) & STR (\%) & $\mathrm{ALH}(\mu \mathrm{m})$ \\
\hline 0 & $43.4 \pm 2.1$ & $59.8 \pm 1.7$ & $50.8 \pm 4.1$ & $14.3 \pm 1.4$ & $26.7 \pm 2.0$ & $24.3 \pm 1.2$ & $53.9 \pm 2.2$ & $2.5 \pm 0.2$ \\
\hline 0.5 & $43.4 \pm 1.1$ & $61.1 \pm 3.2$ & $46.0 \pm 5.0$ & $12.0 \pm 1.2$ & $23.9 \pm 1.6$ & $23.9 \pm 2.5$ & $50.2 \pm 1.9$ & $2.4 \pm 0.2$ \\
\hline 1 & $42.1 \pm 2.5$ & $61.6 \pm 3.4$ & $41.4 \pm 5.5$ & $13.0 \pm 1.3$ & $22.5 \pm 2.3$ & $26.4 \pm 1.0$ & $58.0 \pm 1.9$ & $2.1 \pm 0.2$ \\
\hline 2 & $40.7 \pm 2.3$ & $62.4 \pm 5.2$ & $43.3 \pm 4.0$ & $12.4 \pm 0.6$ & $22.4 \pm 1.6$ & $27.4 \pm 4.7$ & $56.1 \pm 2.0$ & $2.2 \pm 0.2$ \\
\hline
\end{tabular}

VCL: average curvilinear velocity, VSL: straight line velocity, VAP: average path velocity, LIN: linearity (average ratio of VSL/VCL), STR: straightness (average value of the ratio VSL/VAP), ALH: amplitude of the lateral movement of the head. All results show means \pm SEM. 
obtained with $5 \mu \mathrm{g} / \mathrm{mL}$ (Xiao et al., 2016). Significant results were also obtained with low concentrations varying from $0.05 \mu \mathrm{g} / \mathrm{mL}$ to $0.4 \mu \mathrm{g} / \mathrm{mouse}$ of exosomes (Tan et al., 2014; Venugopal et al., 2017). Thus, we aimed to test the effects of low concentrations of cAmMSC-exo in our study, to give more insights about the effects of exosomes at low dosages. However, our results show that cAmMSCexo have no effect on canine post-thaw sperm parameters.

The absence of beneficial effects of cAmMSC-exo could be explained by the cell type and thus the factors they secreted, the possible lack of exosome uptake from spermatozoa cells or by eventual cryo-damages induced on the exosomes, as they can also be affected by the cryopreservation process, resulting in a reduced biological activity (Bosch et al., 2016). Interestingly, exosomes can act on the same tissue differently depending on their concentration and the cell passaging (Venugopal et al., 2017). Furthermore, during the preliminary study, cAmMSC and adipose stem cells were cultured in the same conditions, with the same media but their average exosome concentrations of conditioned media were different $(173 \mu \mathrm{g} /$ $\mathrm{mL}$ for cAmMSC but $615.1 \mu \mathrm{g} / \mathrm{mL}$ for adipose stem cells exosomes). Thus, stem cells origin, cell passage, and environmental factors could influence the exosomal content, yield, and bioactivity (Salomon et al., 2013; Ban et al., 2015; Patel et al., 2016). Clinical studies using amniotic membrane stem cell-derived exosomes are still limited by the exosomal yield and quantification methods, but also by the determination of the right therapeutic dosage (Mehdiani et al., 2015).

\section{CONCLUSION}

In conclusion, this is the first study to evaluate the effects of cAmMSC-exo on sperm cryopreservation. Our results showed that concentrations lower than $2 \mu \mathrm{g} / \mathrm{mL}$ of exosomes have neither harmful nor beneficial effects on canine cryopreservation. These findings give us more insights into the ranges of concentrations at which cAmMSC-exo might be effective. Further studies about cAmMSC-exo extraction methods are needed prior to its effects on sperm cryopreservation for clinical application.

\section{CONFLICTS OF INTEREST}

No potential conflict of interest relevant to this article was reported.

\section{ACKNOWLEDGEMENTS}

This study was supported by RDA (CCAR, \#PJ013954022019, PJ014786012020), Research Institute for Veterinary Science, and the BK21 plus program.

\section{AUTHOR CONTRIBUTIONS}

Conceptualization: Min Jung Kim and Feriel Yasmine Mahiddine

Data curation: Feriel Yasmine Mahiddine

Formal analysis: Feriel Yasmine Mahiddine

Funding acquisition: Min Jung Kim

Investigation: Feriel Yasmine Mahiddine

Methodology: Feriel Yasmine Mahiddine and Ahmad Yar Qamar

Supervision: Min Jung Kim

Validation: Min Jung Kim

Visualization: Min Jung Kim and Feriel Yasmine Mahiddine Writing - original draft: Feriel Yasmine Mahiddine

Writing - review \& editing: Min Jung Kim and Feriel Yasmine Mahiddine

\section{AUTHOR'S POSITION AND ORCID NO.}

FY Mahiddine, DVM, Ms Student, https://orcid.org/0000-0003-3128-6622

AY Qamar, DVM, Mphil, Lecturer, Ph.D., https://orcid.org/0000-0002-0366-3913

MJ Kim, DVM, Mphil, Ph.D, Research Prof., https://orcid.org/0000-0003-0512-155X

\section{REFERENCES}

Alviano F, Fossati V, Marchionni C, Arpinati M, Bonsi L, Franchina M, Lanzoni G, Cantoni S, Cavallini C, Bianchi F, Tazzari PL, Pasquinelli G, Foroni L, Ventura C, Grossi A, Bagnara GP. 2007. Term Amniotic membrane is a high throughput source for multipotent Mesenchymal Stem Cells with the ability to differentiate into endothelial cells in vitro. BMC Dev. Biol. 7:11.

An SY, Jang YJ, Lim HJ, Han J, Lee J, Lee G, Park JY, Park SY, Kim JH, Do BR, Han C, Park HK, Kim OH, Song MJ, Kim SJ, Kim 
JH. 2017. Milk fat globule-EGF factor 8, secreted by mesenchymal stem cells, protects against liver fibrosis in mice. Gastroenterology 152:1174-1186.

Ban JJ, Lee M, Im W, Kim M. 2015. Low pH increases the yield of exosome isolation. Biochem. Biophys. Res. Commun. 461:76-79.

Bosch S, de Beaurepaire L, Allard M, Mosser M, Heichette C, Chrétien D, Jegou D, Bach JM. 2016. Trehalose prevents aggregation of exosomes and cryodamage. Sci. Rep. 6:36162.

Dorronsoro A and Robbins PD. 2013. Regenerating the injured kidney with human umbilical cord mesenchymal stem cellderived exosomes. Stem Cell Res. Ther. 4:39.

Mehdiani A, Maier A, Pinto A, Barth M, Akhyari P, Lichtenberg A. 2015. An innovative method for exosome quantification and size measurement. J. Vis. Exp. (95):50974.

Mitchell R, Mellows B, Sheard J, Antonioli M, Kretz O, Chambers D, Zeuner MT, Tomkins JE, Denecke B, Musante L, Joch B, Debacq-Chainiaux F, Holthofer H, Ray S, Huber TB, Dengjel J, De Coppi P, Widera D, Patel K. 2019. Secretome of adipose-derived mesenchymal stem cells promotes skeletal muscle regeneration through synergistic action of extracellular vesicle cargo and soluble proteins. Stem Cell Res. Ther. 10:116.

Mokarizadeh A, Rezvanfar MA, Dorostkar K, Abdollahi M. 2013. Mesenchymal stem cell derived microvesicles: trophic shuttles for enhancement of sperm quality parameters. Reprod. Toxicol. 42:78-84.

Pan BT and Johnstone RM. 1983. Fate of the transferrin receptor during maturation of sheep reticulocytes in vitro: selective externalization of the receptor. Cell 33:967-978.

Park BJ, Lee HJ, Lee SL, Rho GJ, Kim SJ, Lee WJ. 2018. Establishment of normal reference data of analysis in the fresh and cryopreserved canine spermatozoa. J. Emb. Trans. 33:75-84.

Patel RS, Carter G, El Bassit G, Patel AA, Cooper DR, Murr M, Patel NA. 2016. Adipose-derived stem cells from lean and obese humans show depot specific differences in their stem cell markers, exosome contents and senescence: role of protein kinase $\mathrm{C}$ delta $(\mathrm{PKC} \delta$ ) in adipose stem cell niche. Stem Cell Investig. 3:2.

Qamar AY, Fang X, Kim MJ, Cho J. 2019. Improved post-thaw quality of canine semen after treatment with exosomes from conditioned medium of adipose-derived mesenchymal stem cells. Animals (Basel) 9:865.

Salomon C, Kobayashi M, Ashman K, Sobrevia L, Mitchell MD, Rice GE. 2013. Hypoxia-induced changes in the bioactivity of cytotrophoblast-derived exosomes. PLoS One 8:e79636.

Setyawan EM, Kim MJ, Oh HJ, Kim GA, Jo YK, Lee SH, Choi YB, Lee BC. 2015. Maintaining canine sperm function and osmolyte content with multistep freezing protocol and different cryoprotective agents. Cryobiology 71:344-349.

Tan CY, Lai RC, Wong W, Dan YY, Lim SK, Ho HK. 2014. Mesenchymal stem cell-derived exosomes promote hepatic regeneration in drug-induced liver injury models. Stem Cell Res. Ther. 5:76.

Venugopal C, Shamir C, Senthilkumar S, Babu JV, Sonu PK, Nishtha KJ, Rai KS, K S, Dhanushkodi A. 2017. Dosage and passage dependent neuroprotective effects of exosomes derived from rat bone marrow mesenchymal stem cells: an in vitro analysis. Curr. Gene Ther. 17:379-390.

Xiao GY, Cheng CC, Chiang YS, Cheng WT, Liu IH, Wu SC. 2016. Exosomal miR-10a derived from amniotic fluid stem cells preserves ovarian follicles after chemotherapy. Sci. Rep. 6:23120.

Zhang S, Teo KYW, Chuah SJ, Lai RC, Lim SK, Toh WS. 2019. MSC exosomes alleviate temporomandibular joint osteoarthritis by attenuating inflammation and restoring matrix homeostasis. Biomaterials 200:35-47.

Zhou Y, Xu H, Xu W, Wang B, Wu H, Tao Y, Zhang B, Wang M, Mao F, Yan Y, Gao S, Gu H, Zhu W, Qian H. 2013. Exosomes released by human umbilical cord mesenchymal stem cells protect against cisplatin-induced renal oxidative stress and apoptosis in vivo and in vitro. Stem Cell Res. Ther. 4:34. 